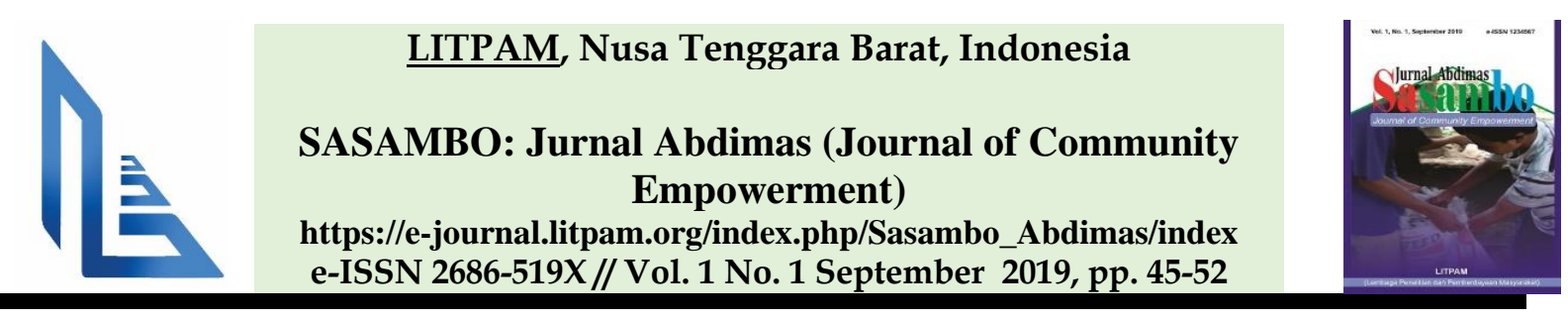

\title{
Pelatihan Budidaya Jamur Tiram Putih (Pleurotus ostreatus) di Pondok Pesantren Hidayaturrahman NW Manggala
}

\author{
${ }^{1}$ Hunaepi, ${ }^{2}$ Taufik Samsuri, ${ }^{3}$ Muhammad Asy'ari, ${ }^{4}$ Baiq Mirawati, ${ }^{5}$ Laras Firdaus, \\ ${ }^{6}$ Herdiyana Fitriani \\ 1,2,4,5\&6Prodi Pendidikan Biologi, FPMIPA, IKIP Mataram, Jl. Pemuda No. 59A, Mataram, \\ Indonesia 83125 \\ ${ }^{3}$ Prodi Pendidikan Olahraga dan Kesehatan, FPOK, IKIP Mataram, J1. Pemuda No. 59A, \\ Mataram, Indonesia 83125
}

Email Korespondensi: hunaepi@ikipmataram.ac.id

\begin{tabular}{|c|c|}
\hline Article Info & Abstract \\
\hline $\begin{array}{l}\text { Received: 11-09-2019 } \\
\text { Revised: 18-09-2019 } \\
\text { Published: 19-09-2019 } \\
\text { Keywords } \\
\text { Aquaculture, Oyster } \\
\text { Mushrooms, Islamic } \\
\text { Boarding Schools }\end{array}$ & $\begin{array}{l}\text { Hidayaturrahman Islamic Boarding School NW Manggala organizes formal } \\
\text { education at the junior high and high school levels. After graduating as santri } \\
\text { who continue to tertiary education and some who quit education and work to } \\
\text { help parents. Therefore, the provision of skills is needed capital to be } \\
\text { independent. The provision of learning skills obtained at school is completed at } \\
\text { a minimum because the teacher (teacher) does not have an entrepreneurial } \\
\text { background. This dedication is done with the aim that the students have the } \\
\text { ability in the cultivation of oyster mushrooms. The method used in this activity is } \\
\text { the diffusion method of science and technology. With work procedures, namely } \\
\text { 1) planning, 2) action, 3) mentoring, 4) evaluation. The result of this activity is } \\
\text { that this service activity is able to improve the skills of students in the cultivation } \\
\text { of oyster mushrooms, increase the interest and motivation of students in terms of } \\
\text { entrepreneurship. }\end{array}$ \\
\hline Infor & Rostran \\
\hline $\begin{array}{l}\text { Sejara } \\
\text { Diteri } \\
\text { Direvi } \\
\text { Dipub }\end{array}$ & \multirow{2}{*}{$\begin{array}{l}\text { Pondok pesantren Hidayaturrahman NW Manggala menyelenggarakan } \\
\text { pendidikan formal setingkat SMP dan SMA. Setelah lulus sebagai santri ada } \\
\text { yang melanjutkan ke jenjang perguruan tinggi dan sebagian ada yang berhenti } \\
\text { melanjutkan pendidikan dan bekerja membantu orang tua. Oleh karena itu bekal } \\
\text { keterampilan sangat dibutuhkan sebagai modal untuk mandiri. Bekal } \\
\text { keterampilan keterampilan yang didapatkan di sekolah sangatlah minim karena } \\
\text { umumnya ustaz (guru) tidak memiliki latar belakang kewirausahaan. pengabdian } \\
\text { ini dilakukan dengan tujuan agar santri memiliki keterampilan dalam hal } \\
\text { pembudidayaan jamur tiram. Metode yang digunakan dalam kegiatan ini adalah } \\
\text { metode difusi ilmu pengetahuan dan teknologi. Dengan prosedur kerja yakni 1) } \\
\text { perencanaan, 2) tindakan, 3) pendampingan, 4) evaluasi. Hasil dari kegiatan ini } \\
\text { adalah kegiatan pengabdian ini mampu meningkatkan keterampilan santri dalam } \\
\text { buidaya jamur tiram, meningkatkan minat dan motivasi santri dalam hal } \\
\text { berwirausaha. }\end{array}$} \\
\hline $\begin{array}{l}\text { Kata kunci } \\
\text { Budidaya, Jamur Tiram, } \\
\text { Pondok Pesantren }\end{array}$ & \\
\hline \multicolumn{2}{|c|}{$\begin{array}{l}\text { Sitasi: Hunaepi, Samsuri, T., Asy'ari, M., Mirawati, B., Firdaus, L. (2019). Budidaya Jamur Tiram di Pondok } \\
\text { Pesantren Hidayaturrahman NW Manggala. Sasambo: Jurnal Abdimas (Journal of Community Service), 1(1), } \\
\text { 45-52. doi: } 10.36312 / \text { sasambo.v1i1.119 }\end{array}$} \\
\hline
\end{tabular}

\section{PENDAHULUAN}

Pondok pensantren Hidayaturrahman NW Menggala Kabupaten Lombok Utara berdiri semenjak tahun 2000 saat ini jumlah santri 491 orang dengan perincian jumlah santri pria 230 
orang dan santri putri 261 orang, serta tenaga guru 53 orang. Pondok pesantren Hidayaturrahman merupakan lembaga pendidikan yang memadukan pendidikan formal dan pendidikan non formal untuk mengembangakan aspek pengetahuan, intelektual, emosional, dan spiritual peserta didik. Pesantren ini memiliki akar tradisi yang sangat kuat di masyarakat dan merupakan produk budaya original masyarakat. Selain itu memiliki kiprah yang sangat banyak dalam mengembangkan nilai-nilai kemanusian dan telah ditunjukkan dengan memberikan sistem pendidikan yang dapat diakses oleh semua golongan masyarakat.

Fua dkk (2016) menyatakan bahwa masyarakat pesantren sebagai subkultural mempunyai etos atau karakteristik budaya yang berbeda dengan yang lain. Etos tersebut merupakan aplikasi dari seperangkat nilai yang dijabarkan dari konsep ketaqwaan yaitu sikap keikhlasan, kebersamaan, kemandirian, kesederhanaan, hemat dan sebagainya yang bernilai positif bagi pemberdayaan ekonomi. Konsep ketaqwaan dapat sebagai modal kuat untuk mengembangkan kemandirian ekonomi pesantren, membentuk pola pikir untuk meningkatkan taraf hidup, dan membangun keterampilan hidup santri. Berdasarakan temuan bahwa di pondok pesantren Hidayaturrahman NW Menggala belum sepenuhnya perangkat nilai-nilai ketaqwaan tersebut dikelola dan diorientasikan kepada etos kerja dan etos ekonomi secara spesifik. Kecendrungan dalam proses pembelajaran sehari lebih dikembangkan ke arah etos sosial secara umum. Kondisi ini nampak dari aktivitas kolektif masyarakat pondok pesantren yang bersifat keagamaan dan ritual murni serta jarang sekali bernuansa pemberdayaan ekonomi sebagai bagian dari dakwah sosial. Selain itu pembinaan dan pelatihan keterampilan hidup santri sangat kurang. Padahal sudah seharusnya tugas pesantren mengintegrasikan dan mengajarkan ilmu pengetahuan dan teknologi sehingga santri tidak hanya memiliki kemampuan dibidang dakwah akan tetapi santri mampu bertahan hidup memenuhi tuntutan masyarakat melalui pendidikan dan pembinaan keterampilan hidup

Pengelolaan pondok pesantren yang masih tradisional serta kondisi pengasuh pondok tidak memiliki latar belakang pendidikan kewirausahaan, sehingga proses pembelajaran yang berlangsung minim akan pelatihan pembentukan keterampilan sebagai bagian dari kewirausaaan. Padahal secara potensi local diwilayah pondok pesantren sangat mendukung untuk diolah dan dikelola sehingga dapat dijadikan kewirausahaan. Potensi lokal yang dimaksud adalah serbuk gergaji yang melimpah, serbuk gergaji yang melimpah selama ini tidak dimanfaatkan sehingga berdampak pada pencemaran lingkungan seperti pencemaaan udara karena adanya aktiftas pembusukan oleh mikroba, $\mathrm{Ph}$ tanah meningkat yang menyebakan tanah menjadi rusak. Pengurangan lahan pertanian dan perkebunan karena penimbunan serbuk gergaji yang berlebihan.

Selain potensi lokal yang melimpah Letak geografis pondok pesantren Hidayaturrahman NW Menggala Kabupaten Lombok Utara berada dibawah kaki gunung pusuk dan rinjani dengan kondisi suhu berkisar $22-28^{\circ} \mathrm{C}$ kondisi suhu tersebut sangat mendukung pertumbuhan miselium jamur tiram. Amelia dkk (2017); Menyatakan bahwa suhu ideal untuk pertumbuhan jamur tiram berkisar $\pm 28^{\circ} \mathrm{C}-31^{\circ} \mathrm{C}$. Mahardian dan Hunaepi (2014) Menyatakan bahwa Pada fase pembentukan miselium, jamur tiram membutuhkan suhu 22-28 $\mathrm{C}$ dan kelembaban $60 \%-80 \%$. Pada fase pembentukan tubuh buah memerlukan suhu $16-22^{\circ} \mathrm{C}$ dan kelembaban $80 \%-90 \%$ dengan kadar oksigen $10 \%$. Selanjutnya Mahadian dan Hunaepi (2015) menyataakan bahwa untuk pertumbuhan jamur idelanya adalah pada kondisi suhu yang setabil dan untuk menstabilkan diperlukan rekayasa suhu dengan menggunakan teknologi evaporate pad. Faktor lingkungan yang mempengaruhi pertumbuhan jamur tiram putih adalah suhu, kelembaban, cahanya, udara, kadar air dan tingat keasamaan pH. Kananga, dkk (2014)

Dalam pemanfaatan serbuk gergaji sebagai media tanam jamur tiram dibutuhkan beberapa bahan tambahan seperti dedak halus, tepung kanji, kapur (CaCo3), Gips (CaSO4), Tepung Jagung, dan Glukosa. Hunaepi, dkk (2018). Adanya potensi lokal dan letak geografis pondok pesantren Hidayaturrahman NW Menggala sangat memungkinkan untuk dilakukan pembinaan keterampilan santri dalam pembudidayaan jamur tiram. Sehingga santri dapat 
mandiri secara ekonomi, selain itu dengan pembinaan keterampilan hidup secara berkelanjutan akan dapat membagkitkan minat, motovasi dan semangat wirausaha para santri untuk kemudian diarahkan menuju pengembagan pengelolaan usaha-usaha ekonomi bila santri kembali kemasyarakat setelah lulus dari pondok pesantren.

\section{METODE}

Adapun Program Kemitraan pada Masyarakat (PKM) dilaksanakan dengan metode difusi ilmu pengetahuan dan teknologi. Waktu pelaksanaan program kemitraan pada masyarakat dilaksanakan pada bulan mei s/d september 2019. Pelaksanaan kegiatan dilakukan dengan beberapa langkah antara lain;

1. Perencanaan meliputi;

a. Survei dan analisis lokasi kegiatan; kegiatan ini diperlukan untuk mendapatkan informasi kondisi sosial budaya pesantren, karakteristik santri, kondisi lingkungan, peta wilayah pesantren. Informasi ini sangat diperlukan untuk merancang pelaksanaan program PKM yang efisien dan efektif.

b. Sosialisasi kegiatan melalui kegiatan FGD (Fokus Grup Diskusi)

c. Persiapan alat dan bahan; Tim PKM dan anggota mitra secara bersama-sama mempersiapkan semua bahan dan peralatan yang diperlukan selama pelaksanaan program PKM.

d. Pengadaan media belajar; untuk memudahan proses penyuluhan dan pelatihan maka diberikan buku pedoman praktis budidaya jamur tiram

2. Tindakan meliputi;

a. Peningkatan pengetahuan budidaya jamur tiram kepada kelompok mitra melalui kegiatan penyuluhan, metode yang digunakan adalah ceramah, Tanya jawab, dan diskusi. Materi yang disampaikan antara lain; 1) mengenal jamur tiram dan prospek bisnis jamur tiram, 2) pembuatan kumbung jamur, 3) teknik budidaya jamur tiram, dan 4) panen dan pascapanen. Untuk mengetahui adanya peningkatan pengetahuan atas materi yang disampaikan, mitra diberikan pretes dan posttest.

b. Pelatihan, kegiatan ini bertujuan untuk meningkatkan keterampilan mitra dalam hal ini santri, guru dan pengasuh dalam menjalankan usaha produksi jamur tiram agar dapat mendapatkan keuntungan secara berkesinambungan. Untuk mencapai tujuan tersebut maka dilakukan kegiatan pendampingan pembuatan rumah jamur (kumbung), inkubasi, pemeliharaan jamur tiram, panen dan pascapanen

c. Pendampingan; kegiatan ini dilakukan untuk meningkatkan keterampilan dan kemandirian mitra dalam pembudidayaan jamur tiram. Pendampingan dilakukan secara berkelanjutan sampai mitra mandri dalam budidaya.

Untuk tahap awal usaha pembudidayaan jamur tiram, mitra tidak lansung membuat baglog jamur tiram dari awal, melainkan mitra diberikan bantuan 1000 buah baglog jamur tiram. Ini bertujuan agar usaha dan produksi jamur tiram bisa berjalan. Hunaepi, dkk (2018) Untuk pengusaha pemula sebaiknya membeli baglog yang sudah jadi untuk memperkecil kemungkinan gagal.

\section{HASIL DAN PEMBAHASAN}

Pengabdian dilakukan dengan terlebih dahulu mengadakan diskusi dengan tim PkM untuk menentukan langkah kerja yang akan dilakukan, adapun langkah awal kegiatan PkM adalah sebagai berikut

\section{Observasi}

Sebelum kegitaan pelatihan dilakukan terlebih dahulu tim PKM melakukan observasi dan dikusi dengan mitra dalam hal ini pengurus pondok pesantren Hidayaturrahman NW Manggala, ini bertujuan untuk mendapatkan kesepakatan tentang proses pelatihan, adapun hasil kegiatan observas adalah 1) disepakati tentang kegiatan pelatihan budidaya jamur tiram, 
2) lokasi kegiatan pelatihan, 3) mekanisme dan jadwal pelatihan, dan 4) lokasi pembudidayaan jamur tiram.

Kegiatan pelatihan pembudidayaan jamur tiram melibatkan 20 orang yang terdiri dari santri, guru, dan pengelola pondok pesantren. 20 orang yang terlibat diharapkan kedepannya dapat memberikan motivasi bagi santri-santri yang ada di pondok pesantren untuk mengembangkan kewirausahaan sebagai bagian dari pengembangan keterampilan di bidang budidaya jamur tiram. Ni'matuzahroh dkk (2017) budidaya jamur tiram dipondok pesantren dapat berdampak pada peningkatan motivasi dan produktifitas santri dalam bidang kewirausahaan.

Lokasi kegiatan pelatihan terbagi menjadi dua tempat yakni di aula pondok pesantren dan di luar Aula. Di gunakan Aula untuk memudahkan penyampaian materi terkait dengan pembudidayaan jamur, perawatan dan penangana panen dan pasca panen. Sedangkan di luar Aula untuk melakukan praktik pembuatan media jamur (baglog) tiram. Kegiatan penyuluhan dan pelatihan ini dilakukan setiap hari jumat, sabtu, dan minggu disesuaikan dengan kegiatan utama santri, guru dan pengelola pondok. Adapun jadwal kegiatan sebagai berikut;

Tabel 1. Jadwal Kegitan penyuluhan dan pelatihan budidaya jamur tiram di pondok pesantren Hidayaturrahman NW Manggala.

\begin{tabular}{|c|c|c|c|}
\hline No & Hari & Kegiatan & Pelaksanaan \\
\hline \multicolumn{4}{|c|}{ Penyuluhan } \\
\hline 1 & Jumat & $\begin{array}{l}\text { Mengenal Jamur tiram, } \\
\text { Prospek Bisnis Jamur Tiram, } \\
\text { Pembuatan kumbung jamur } \\
\text { tiram }\end{array}$ & $\begin{array}{l}\text { Kegiatan ini dilaksanakan selama } \\
\text { 4 Jam }\end{array}$ \\
\hline 2 & Sabtu & $\begin{array}{l}\text { Teknik budidaya jamur tiram, } \\
\text { panen dan pasca panen }\end{array}$ & $\begin{array}{l}\text { Kegiatan ini dilaksanakan selama } \\
5 \text { Jam }\end{array}$ \\
\hline \multicolumn{4}{|c|}{ Pelatihan } \\
\hline 1 & Sabtu & Pembuatan kumbung jamur & $\begin{array}{l}\text { Kegiatan ini dilaksanakan selama } \\
2 \text { hari yakni hari sabtu dan } \\
\text { minggu. }\end{array}$ \\
\hline 2 & Jumat & Penataan baglog jamur tiram & Kegitan ini dilakanakan 2 jam \\
\hline \multicolumn{4}{|c|}{ Pendampingan } \\
\hline 1 & & Perawatan & $\begin{array}{l}\text { Kegiatan pendampingan } \\
\text { perawatan dilaksanakan } 1 \text { kali } \\
\text { pertemuan, dan selanjutnya mitra } \\
\text { yang melakukan perawatan pada } \\
\text { baglog jamur }\end{array}$ \\
\hline 2 & & Panen dan pasca panen & $\begin{array}{l}\text { Kegiatan ini dilakukan setelah } 2 \\
\text { bulan masa inkubas di dalam } \\
\text { kumbung }\end{array}$ \\
\hline
\end{tabular}

Hasil observasi didapatkan gambaran umum tentang kondisi pondok pesantren yang akan dijadikan lokasi pengabdian. Letak geografis pondok berada di pinggir hutan, menjadikan lokasi ini sangat cocok untuk mengembangkan budidaya jamur tiram yang memerlukan suhu udara berkisar antara $22-28^{\circ} \mathrm{C}$ dengan kelembaban 60-70 \% dan fase pembentukan tubuh buah memerlukan suhu udara sama antara $22-28^{\circ} \mathrm{C}$. Ismail (2018); Rosado dkk (2002); Amelia (2017) syarat tumbuh jamur tiram adalah lingkungan yang sejuk (suhu $28-32^{\circ} \mathrm{C}$ ) dan lembab. Suhu yang teralu dingin menyebakan miselium tumbuh lambat. Sedangkan suhu yang teralau panas dapat membuat miselium jamur tiram mati. Syarat berikutnya adalah lingkungan yang lembab (bukan pengap) dengan kadar uap air berkisar antara 80\% - 90\%. Jika kadar uap air di bawah $60 \%$ miselium dapat kering/mati. Sebaliknya jika terlalu tinggi dapat menyebabkan baglog 
kontaminasi bahkan busuk. Setelah didapatkannya data observasi, tim PKM selanjutanya menyepakati posisi pembangunan kumbung, Adapun posisi seperti yang terlihat pada gambar berikut

\section{Pelaksanaan Kegiatan}

Kegiatan ini memberikan penjelasan yang konprehensif tentang; 1) mengenal jamur tiram dan prospek bisnis jamur tiram 2) pembuatan kumbung jamur, 3) teknik budidaya jamur tiram, dan 4) panen dan pascapanen. Kegiatan penyuluhan ini dilakukan sebelum melakukan praktik hal ini dimaksudkan agar proses praktik lebih mudah dilaksanakan, kegiatan penyampaikan materi ini dilakukan dengan ceramah dan demonstrasi. Kegiatan dilakukan di Aula pondok.

Kegiatan penyuluhan dilaksankan sesuai dengan jadwal yang telah disepakati, yakni hari jumat, sabtu dan minggu. Adapun indikator keberhasilan dari kegitan ini adalah;

1) Mitra memahami tentang jamur tiram dan prospek bisnis jamur tiram di wilayah Lombok

2) Mitra memahmi bentuk-bentuk bangunan kumbung jamur yang terbuat secara permanen, ataupun semipermanen

3) Mitra memahami cara budidaya jamur tiram mulai dari penempatan baglog di rak kumbung, perawatan jamur tiram pada saat pembudidayaan dalam kumbung

4) Mitra memahmi teknik pemanenan dan penanganan pasca panen jamur tiram

Untuk melengkapi data tentang peningkatan pemahaman mitra sebelum dilakukan penyuluhan mitra diberikan pretes dan sesudah kegiatan diberikan posttest. Berikut disajikan data analisis pretes dan posttest dengan menggunakan $N$-Gain

Tabel. Data analisis pretes dan postest Kelompok mitra

\begin{tabular}{ccccc}
\hline No & Pree Tes & Pos Tes & $N$-Gain & Katagori \\
\hline 1 & 11.4 & 72.2 & 0.69 & Tinggi \\
\hline
\end{tabular}

Tabel di atas menunjukkan bahwa adanya peningkatan pemahaman mitra tentang materi yang diberikan melalui kegiatan penyuluhan, tingkat pemahaman sebelum diberikan penyuluhan mencapai rata 11.4 sedangkan sesudah penyuluhan mencapai rata-rata 72.2 hal tersebut menunjukkan adanya peningkatan pemahaman mencapai 0,69 dengan katagori (tinggi) setelah kegiatan penyluhan dan evaluasi kegiatan selesai, kegiatan selanjutnya adalah apliaksi teori yang telah diberikan yakni pembuatan kumbung.

Pembuatan kumbung dilakukan setelah kegitan pembekalan atau penyuluhan tentang desain rumah jamur atau kumbung jamur. Kumbung jamur dibuat sendiri oleh mitra dan didampingi oleh tim PKM dengan bahan-bahan yang digunakan antara lain, Kayu, Bambu, Pagar babu (bedek), spandek, dll. Karena posisi pondok berada di perbukitan dan pinggir hutan maka rumah jamur dibuat paling atas hal ini dimaksudkan agar sirkuliasi udara dan pencahayan dapat maksimal sesuai kebutuhan pertumbuhan jamur tiram. Adapun bentuk rumah jamur yang dibuat seperti yang terlihat pada Gambar 1.
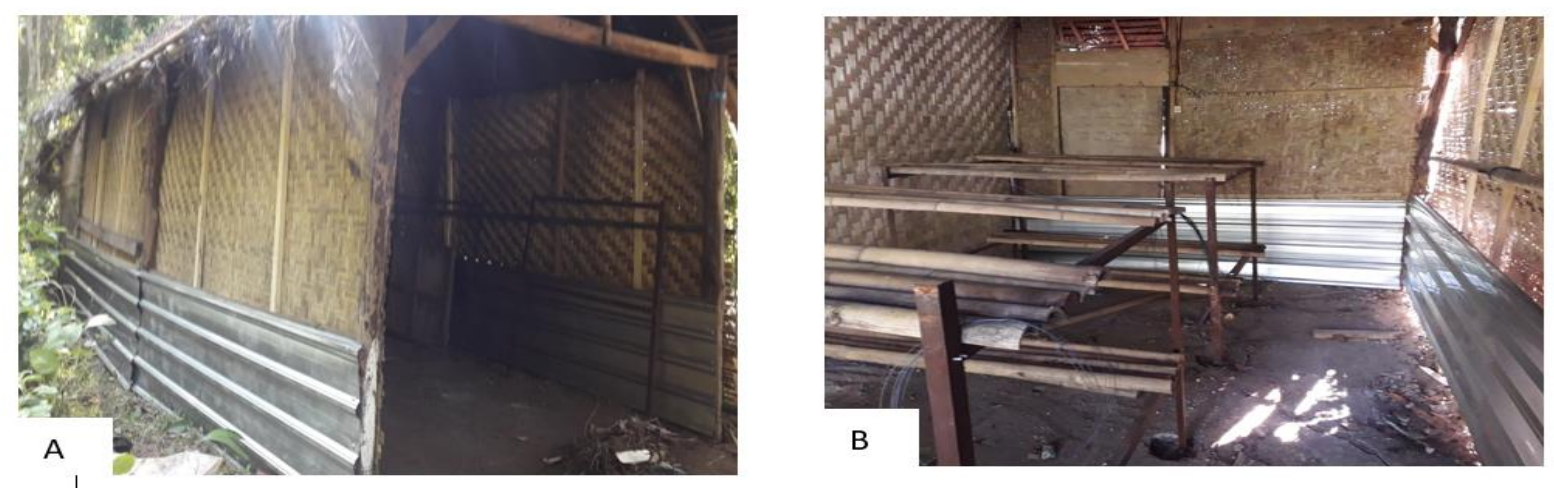

Gambar 1: (a) bagunan/rumah jamur yang telah jadi, (c) tampak dalam rumah jamur, dan rak jamur yang telah jadi. (Sumber: doc. pengabdian) 
Kumbung yang dibuat berukuran $6 \times 4 \mathrm{~m}^{2}$ dengan kapasitas 1000 buah baglog. Lokasi kumbung berada di bagian belakang pondok santri, ini dimaksudkan agar sirkulasi udara baik, dan suhu konstan, sesuai dengan kebutuhan pertumbuhan jamur tiram. Letak kumbung yang baik adalah terletak pada loaksi yang terbuka, dan jauh dari bahan-bahan yang dapat mengkontaminasi media jamur. Seperti Tempat pembuangan sampah (TPS), kandang ternak dan lokasi-lokasi yang memungkinkan dapat mengkontaminasi media jamur. Hunaepi (2014) lokasi pembudidayaan jamur sebaiknya bebas dari pencemaran udara, misalnya tidak berdekatan dengan pabrik, pembuangan sampah akhir, atau jalan raya.

Setelah kumbung jadi, tim PKM melakukan evaluasi untuk melihat apakah rumah jamur yang dibuat oleh mitra sudah memenuhi syarat pertumbuhan untuk pertumbuhan jamur tiram. Hasil evaluasi menunjukkan bahwa rumah jamur yang dibuat oleh tim mitra sudah memenuhi standar untuk pembudidayaan jamur tiram.

Rumah jamur yang telah jadi tidak langsung di gunakan, akan tetapi dilakukan pongkondisian, hal tersbut bertujuan untuk meninjau perubahan-perubahan suhu dalam kumbung, sehingga memudahkan untuk mengkondisikan kumbung jamur jika terjadi perubahan suhu yang ekstrim atau tidak sesuai dengan kebutuhan pertumbuhan jamur. Setelah satu minggu penataan baglog jamur tiram dirak-rak kumbung dimulai, penataan dilakukan dengan cara vertical. Widodo, dkk (2016) penataan baglog secara vertical dapat meningkatkan kapasitas produksi jamur.

Penempatan baglog di dalam kumbung tidak dilakukan secara serentak akan tetapi dengan cara bertahap, ini bertujuan untuk menghindari panen raya yang terjadi akibat waktu produksi bersamaan. Setelah dilakukan penempatan baglong selanjutnya mitra diberikan pembekalan praktik tentang perawatan selama proses inkubasi dalam kumbung sampai masa panen tiba.

Perawatan dan control dilakukan setiap hari oleh mitra, untuk mengamati pertumbuhan jamurnya. Pengecekan kondisi lingkungannya, termasuk suhu dan kelembabanya. Sirkulasi udara. Hal ini agar dapat diketahui secara dini apabila terdapat jamur yang pertumbuhanya terganggu maupun adanya seragam hama dan penyakit.

Perawatan dan control dilakukan setiap hari oleh mitra, meliputi penyiraman jika kondisi suhu ruangan meningkat, selain itu penyiraman bertujuan untuk menjaga kelembaban ruangan kumbung jamur. Pengontrolan juga bertujuan untuk menjaga kondisi baglong dari hama yang dapat menyebabkan kegagalan pertumbuhan badan buah jamur.

Setelah masa panen tim PKM mendampingi mitra untuk melakukan pemanenan dan penanganan pasca panen jamur tiram. Panen dan penanganan pascapanen merupakan kegiatan akhir dari kegiatan budidaya jamur. Teknik pemanenan sangat berpengaruh terhadap kualitas jamur yang dipanen, termasuk didalamnya kualitas dan daya tahan jamur teknik panen yang kurang baik dapat mengakibatkan kerusakan pada media tumbuh jamur yang pada akhirnya akan mengurangi prduktivitas jamur yang dihasilkan

Pemanenan jamur dilakukan dengan mencabut seluruh tanaman yang ada sampai akarnya hingga bersih. Pemanenan tidak dapat dilakukan dengan cara memotong bagian atau cabang jamur yang berukuran besar saja, sebab sisa jamur yang ditinggalkan tidak akan tumbuh lagi. Pencabutan jamur sampai ke akarnya dilakukan untuk menghindari adanya sisa akar atau batang tertinggal sehingga dapat merusak media (media menjadi busuk) yang dapat mengakibatkan rusaknya pertumbuhan jamur selanjutnya.

Pemanenan dilakukan setelah dua hari setelah tunas muncul dengan mencabut seluruh bagian jamur yang ukurannya sudah optimal. Setelah dicabut, bersihkan serbuk kayu yang menempel pada bagian akar. Pendampingan selanjutnya adalah penanganan pasca panen yakni pengemasan jamur tiram. Proses pengemasan dilakukan oleh kelompok mitra dengan cara mengemas menggunakan kantong plastik kedap udara, ini bertujuan agar tahan lebih lama dan tampak lebih menarik. Pada produksi tahap awal hasil budidaya dikemas kedalam kantong 
plastik berukuran 1 ons dan dijual di sekitar wilayah pondok, selain itu dijadikan lauk oleh pengelola pondok yang disajikan untuk santri.

Tahap terahir dari kegiatan PKM adalah mengevaluasi secara keseluruhan proses budidaya jamur. Dari proses evaluasi terdapat beberapa temuan antara lain, 1) santri termotivasi untuk melakukan pembudidayaan, akan tetapi waktu yang tersedia terlalu sedikit sehingga waktu luang yang dimiliki perlu dimenejeman dengan baik, agar santri dapat melakukan aktivitas pengembangan live skill kewirausahaan, 2) tidak adanya matapelajaran tentang kewirausahaan disekolah menyebabkan siswa kurang memahami tentang pentingnya berwirausaha, kondisi ini mengisyaratkan bahwa matapelajaran kewirausahaan perlu di masukkan atau di integrasikan dengan matapelajaran lain.

\section{Respon Pelaksanaan Kegiatan}

Kegiatan PKM yang dilaksankaan di pondok pesantren Hidayaturrahman NW Manggala, mendapat respon yang sangat baik oleh pimpinan, pengurus dan dan santri pondok. Hal tersebut terlihat dari semangat dan motivasi dalam mengikuti kegiatan PKM budidaya jamur tiram. Pendampingan mitra terus dilakukan oleh tim PKM untuk mendapatakan hasil produksi jamur tiram yang lebih maksimal. Hasil dari kegiatan ini telah mampu memberikan peluang dan memberikan nilai tambah bagi mitra, dari segi pengetahuan dan keterampilan dalam hal budidaya jamur tiram.

\section{KESIMPULAN}

Kegiatan pelatihan dan pendampingan budidaya jamur tiram, terlaksana dengan baik hal tesebut terlihat dai indikator capaian bahwa mitra telah memahami pengetahuan tentang teknik budidaya jamur tiram, serta telah menunjukkan kemajuan melalui kegiatan pelatihan dan praktik budidaya jamur tiram. Terdapat beberapa kendala sehingga sampai dengan masa panen selesai untuk tahap awal, belum mendapatkan hasil panen yang maksimal, hal tersebut diakibatkan oleh kondisi suhu yang berubah-ubah sehingga mempengaruhi kelembaban didalam kumbung. Usaha menstabilkan kelembaban sudah dilakukan oleh mitra, namun belum mencapai kelembaban yang optimal untuk pertumbuhan jamur tiram.

\section{SARAN}

Untuk memaksimalkan hasil panen, maka suhu dan kelembaban udara dalam rumah kumbung perlu di manipulasi sesuai dengan kebutuhan pertumbuhan jamur tiram. Budidaya jamur tiram di pondok dapat dijadikan salah satu alternative pengembangan life skill kewirausahaan santri, selain itu dapat dijadikan sebagai salah satu sumber pemasukan, sehingga keungan pondok dapat stabil.

\section{UCAPAN TERIMA KASIH}

Terimakasih penulis sampaikan kepada Kementrian Riset dan Teknologi Pendidikan Tinggi (KEMENRISTEKDIKTI) yang telah memberikan bantuan dana dalam kegiatan Pengabdian kepada Masyarakat tentang Membangun Kemandirian Ekonomi Santri Pondok Pesantren Hidayaturrahman Pasca Gempa Melalui Pendidikan Life Skill Budidaya Jamur Tiram. Ucapan terimakasih juga disampaikan kepada LPPM IKIP Mataram, dan Program Studi Pendidikan Biologi FPMIPA IKIP Mataram.

\section{DAFTAR PUSTAKA}

Amelia. F., Frdinand. J., Maria. K., Waluyan. G.M., dan Sari. I. 2017. Pengaruh Suhu dan Intensitas Cahaya Terhadapa Pertumbuhan Jamur Tiram di Tangerang. Jurnal Biogenesis Vol. 5. No. 12017 hal. 1-6.

Fua. L.J., Wahyuni. I., Hadisi. L., Insawan. H. dan Lestari. S.A. 2016. Pendidikan Life Skill Komunitas Santri Melalui Budidaya Jamur Merang Berbasis Enterpreneurship Di 
Pondok Pesantren Al-Jannah Konawe Selatan. Jurnal Al-Izzah. Vol 11. No 2. Th 2016. Hal. 1-18

Hunaepi, Dharmawibawa. D. I., dan Asy'ari M. 2018. Pemberdayaan Kelompok Budidaya Jamur Tiram dalam Pemanfaatan Limbah Baglog Menjadi Pupuk Organik. Prosiding Seminar Nasional. Hal 727-733

Ismail (2018) Modul 1: Sekilas Budidaya Jamur Tiram. (tidak dipublikasi) Program Studi Pendidikan Biologi. FPMIPA IKIP Mataram.

Kenanga. P., Pambudi. A., dan Puspitasari. L.R. 2014. Perbandingan Pertumbuhan Jamur Tiram Putih di Kumbug Ciseeng dan Universitas Al-Azhar Indonesia. Jurnal Al.Kauniah. Vol . 7 No 2 Th 2014. Hal. 94-98

Mahardian. G. dan Hunaepi.2015. Mendongkrak Penen Tiram. Trubus 547 juni 2015/XLVI. Hal. 46-48

Mahardian. G. dan Hunaepi.2014. Pengaruh Penggunaan evaporative pad Terhadap Iklim Mikro pada Rumah Jamur Tiram (Pleurotus ostreatus) Berdinding Jerami Di Musim Kemarau. Jurnal Bioscientist. Vol 2. No 1. Th 2014. Hal 240-249.

Ni'matuzahroh, Fatimah, Nur Indradewi Oktavitri, Moch. Affandi, Muhammad Hilman Fu'adil Amin, Prasetyo Handrianto (2017) Peningkatan produktivitas kelompok santri melalui Budidaya jamur tiram putih di Pondok Pesantren Darul Huda, Jabon, Sidoarjo. Seminar Nasional Hasil Pengabdian kepada Masyarakat (SENIAS) 2017 - Universitas Islam Madura. Hal. 1-6

Rosado, F.R., Carbonero, E.R., Kemmelmeier, C., Tischer, C.A. \& Iacomini, M. 2002. A partially 3-0-methylated $(1 \rightarrow 4)$ linked a-D-glucan and a-D-mannan from Pleurotus ostreatus sing. FEMS Microbiological Letters 212: 261-265.

Widodo, Diah Rina Kamardiani, Lis Noer Aini. (2016) Kewirausahaan Jamur Tiram Di Pondok Pesantren. Jurnal BERDIKARI. 4(1) hal. 23-30. https://doi.org/10.18196/bdr.413 